\title{
Introducing robot-assisted laparoscopic donor nephrectomy after experience in retroperitoneal endoscopic living donor nephrectomy approach
}

\author{
Minh Sam Thai ${ }^{1}$, Quy Thuan $\mathrm{Chau}^{2}$, Khac Chuan Hoang ${ }^{2}$, Xuan Thai $\mathrm{Ngo}^{1}$, Trong Hien Nguyen ${ }^{2}$, Kinh Luan Thai ${ }^{1}$, \\ Duc Huy Vu², Le Quy Van Dinh ${ }^{2}$, Ho Yee Tiong ${ }^{3}$, Thanh Tuan Nguyen ${ }^{1}$ \\ 1Department of Urology, Cho Ray Hospital, University of Medicine and Pharmacy at Ho Chi Minh City, Ho Chi Minh City, Vietnam \\ ${ }^{2}$ Department of Urology, Cho Ray Hospital, Ho Chi Minh City, Vietnam \\ ${ }^{3}$ Department of Urology, National University Hospital, Singapore
}

Background: This study aims to assess safety and efficacy of introducing robot-assisted laparoscopic donor nephrectomy (RALDN) to the standard retroperitoneal endoscopic living donor nephrectomy (RELDN) at a single institution transplant program.

Methods: Data were collected prospectively from 68 consecutive living kidney donors ( 14 for RALDN subgroup and 54 RELDN subgroup) at a transplant center from February 2018 to September 2019. Patient baseline demographics, radiological findings, perioperative donor outcomes, recipient outcomes, and complications were recorded, and these parameters were compared between the two surgical groups.

Results: For the entire group, mean age \pm standard deviation was $51.4 \pm 8.9$ years (range, $29-68$ years); $44.1 \%$ were males; mean body mass index (BMI) was $22.6 \pm 2.3 \mathrm{~kg} / \mathrm{m}^{2}$ (range, $15.6-27.3 \mathrm{~kg} / \mathrm{m}^{2}$ ); and there were $57(84 \%$ ) left kidneys. Preoperatively, there was no significant differences $(P>0.05)$ between the two donor groups including gender, BMI, kidney side, hilar anatomy, and American Society of Anesthesiologists status. For perioperative outcomes, there was no significant differences $(P>0.05)$ comparing RALDN and RELDN respectively for warm ischemic time ( $4.7 \pm 1.4$ minutes vs. $4.8 \pm 1.4$ minutes), operative time (232 \pm 43 minutes vs. $217 \pm 41$ minutes), hemoglobin drop $(7.5 \pm 5.8 \mathrm{~g} / \mathrm{L}$ vs. $8.5 \pm 7.2 \mathrm{~g} / \mathrm{L})$, postoperative complications ( $7.1 \%$ vs. $7.4 \%$ ), the donor blood creatinine at 1 month $(1.13 \pm 0.22 \mathrm{mg} / \mathrm{dL}$ vs. $1.22 \pm 0.26 \mathrm{mg} / \mathrm{dL})$, and the recipient blood creatinine at 1 month $(1.25 \pm 0.28$ $\mathrm{mg} / \mathrm{dL}$ vs. $1.41 \pm 0.38 \mathrm{mg} / \mathrm{dL})$.

Conclusions: This study showed that RALDN can be safely introduced into living donor program experienced in laparoscopic donor nephrectomy.

Corresponding author: Thanh Tuan Nguyen

E-mail: Thanhtuan0131@gmail.com

(C) The Korean Society for Transplantation

This is an Open Access article distributed under the terms of the Creative Commons Attribution Non-Commercial License (http://creativecommons.org/licenses/by-nc/4.0/) which permits unrestricted non-commercial use, distribution, and reproduction in any medium, provided the original work is properly cited. 